\title{
THE TYPE OF PHARMACEUTICAL PAYMENTS TO PHYSICIANS AFFECTS PRESCRIPTION BEHAVIOR OVER TIME
}

\author{
Janice Winch, Pace University, Lubin School of Business, New York, N.Y., U.S.A. \\ John Carter, Pace University, Lubin School of Business, New York, N.Y., U.S.A.
}

dx.doi.org/10.18374/IJBR-20-3.4

\begin{abstract}
The purpose of this paper is to examine how payments by pharmaceutical companies to physicians are related to prescription behavior in the years following the passage of the Physician Payments Sunshine Act of 2010. The study analyzes data from the Open Payments data and the Medicare Part D prescription data from 2014-2017, to measure the effect of the Act on behavior over time. In particular, it examines the relationship between payments made in one year by 18 of the largest drug manufacturers and the prescription rate and value of the drugs promoted by those manufacturers in that year and the following year. The main findings are that the proportion of physicians receiving drug-related industry payments to physicians has decreased from 2014 to 2017; for most manufacturers, a greater percentage of physicians who received other-than-food payments prescribed the payer's drugs than the percentage receiving food-only payments, which in turn exceeded the percentage for those not receiving payments; this relationship held true for the value of prescriptions written as well, persisting when controlling for the specialty of the physician.
\end{abstract}

Keywords: Drug industry - physician financial relationship; Medicare Part D; Sunshine Act; Open Payments 